\title{
Mobilidade noturna: estudo sobre os circuitos urbanos noturnos na cidade do Rio de Janeiro ${ }^{1}$
}

\author{
Marcos Paulo Ferreira de Góis ${ }^{2}$ \\ Universidade Federal Fluminense \\ marcosgois@id.uff.br \\ Recibido: 15 de febrero de 2017 \\ Aceptado: 12 de octubre de 2017 \\ Disponible en línea: 30 de junio de 2018
}

1 Este artigo resulta de um trabalho de investigação financiado pelo Conselho Nacional de Pesquisa brasileiro (CNPq) e pela Fundação Carlos Chagas de Amparo à Pesquisa do Estado do Rio de Janeiro (Faperj) e realizado entre os anos de 2011 e 2015.

2 Doutor em Geografia e Professor do Magistério Superior da Universidade Federal Fluminense, Instituto de Educação de Angra dos Reis, Rio de Janeiro (Brasil). 


\title{
Movilidad nocturna: estudio sobre los circuitos urbanos nocturnos en la ciudad de Rio de Janeiro
}

\section{Resumen}

El objetivo de este artículo es entender algunas estrategias de la población para desplazarse durante el horario nocturno en la ciudad de Rio de Janeiro. En este sentido, la investigación involucró procedimientos de observación directa de los circuitos, medios de locomoción, prácticas y sus respectivos horarios, ritmos e interacciones sociales. En medio de la multiplicidad de estrategias se percibió que algunos patrones organizan los circuitos, denotando un profundo sentido relacional en la movilidad y su dependencia de los sistemas de transporte. La asociación de la movilidad nocturna hacia los centros de ocio es una característica que marca los principales patrones y circuitos de la noche de Rio, en las más diferentes escalas de manifestación del fenómeno, revelando un reto para la gestión urbana en un escenario de expansión de las relaciones sociales en el horario nocturno.

Palabras clave: movilidad urbana; vida nocturna; sociabilidad; prácticas espaciales

\section{Nocturnal mobility: a study on urban night circuits in Rio de Janeiro}

\begin{abstract}
The aim of this article is to understand some strategies of the population to move during the night in the city of Rio de Janeiro. In this sense, the research involved procedures of direct observation of circuits, ways of moving across the city, practices and their respective schedules, rhythms and social interactions. Through the multiplicity of strategies, it was perceived that some patterns establish circuits, denoting a deep relational sense in the mobility and its dependence on the transport systems. The association of night mobility with leisure centers is a representative feature that marks the main patterns and circuits of Rio's nightlife, at the most different manifestations of the phenomenon, revealing a challenging situation for urban administration in a scenario of expansion of social relations in the nighttime.
\end{abstract}

Keywords: urban mobility; nightlife; sociability; spatial practices

\section{Mobilidade noturna: estudo sobre os circuitos urbanos noturnos na cidade do Rio de Janeiro}

\section{Resumo}

O objetivo deste artigo é compreender algumas estratégias da população para se deslocar durante o período noturno na cidade do Rio de Janeiro. Neste sentido, a pesquisa envolveu procedimentos de observação direta dos circuitos, meios de deslocamento, práticas e seus respectivos horários, ritmos e interações sociais. Em meio à multiplicidade de estratégias se percebeu que alguns padrões organizam os circuitos, denotando um profundo sentido relacional na mobilidade e sua dependência dos sistemas de transporte. A associação da mobilidade noturna aos centros de lazer é uma característica que marca os principais padrões e circuitos da noite do Rio, nas mais diferentes escalas de manifestação do fenômeno, revelando um desafio para a gestão urbana em um cenário de expansão das relações sociais no período noturno.

Palavras-chave: mobilidade urbana; vida noturna; sociabilidade; práticas espaciais 


\section{Introdução}

Mais de doze milhões de pessoas habitam a região metropolitana do Rio de Janeiro, sendo que mais da metade se movimenta diariamente em direção aos seus postos de trabalho, locais de estudo, centros de comércio e outros lugares. O sítio urbano é caracterizado pela imposição dos maciços litorâneos e pelo estreitamento das planícies na face sul, com áreas de baixadas planas no interior (figura 1). Esta condição do sítio geográfico se torna um fator significativo para a dispersão dos sistemas de transporte, os quais se dirigem em sentidos similares para os centros urbanos, administrativos, comerciais e de serviços. Esta demarcada concentração em poucos centros acarreta um variado cardápio de problemas para a mobilidade cotidiana da população: engarrafamentos, lentidão, superlotação, esgotamento da capacidade de transporte etc.

De forma bem simplificada podemos sugerir que o tema da mobilidade urbana tem sido um dos dilemas centrais enfrentados pela população urbana de grandes cidades como o Rio, sendo, portanto, uma questão central para a reflexão contemporânea sobre a vida metropolitana. Há um grande debate sobre o uso de veículos particulares e sobre as estratégias de resolução a partir da importação de modelos de países desenvolvidos (Gakenheimer, 1999). Há também discussões em torno das novas atribuições dos transportes públicos e do controle dos governos locais sobre o problema da mobilidade (Docherty, Shaw e Gather, 2004), o que acaba por fornecer um desdobramento no que diz respeito ao pedestrianismo e ao uso de veículos não motorizados (Lorimer, 2011). De fato, o tema da mobilidade urbana aparece como um dos eixos centrais da pesquisa social desde os fins da década de 1980, a partir de discussões mais tradicionais sobre sistemas de transportes urbanos e movimentos pendulares ou commuting (Edensor, 2011). 


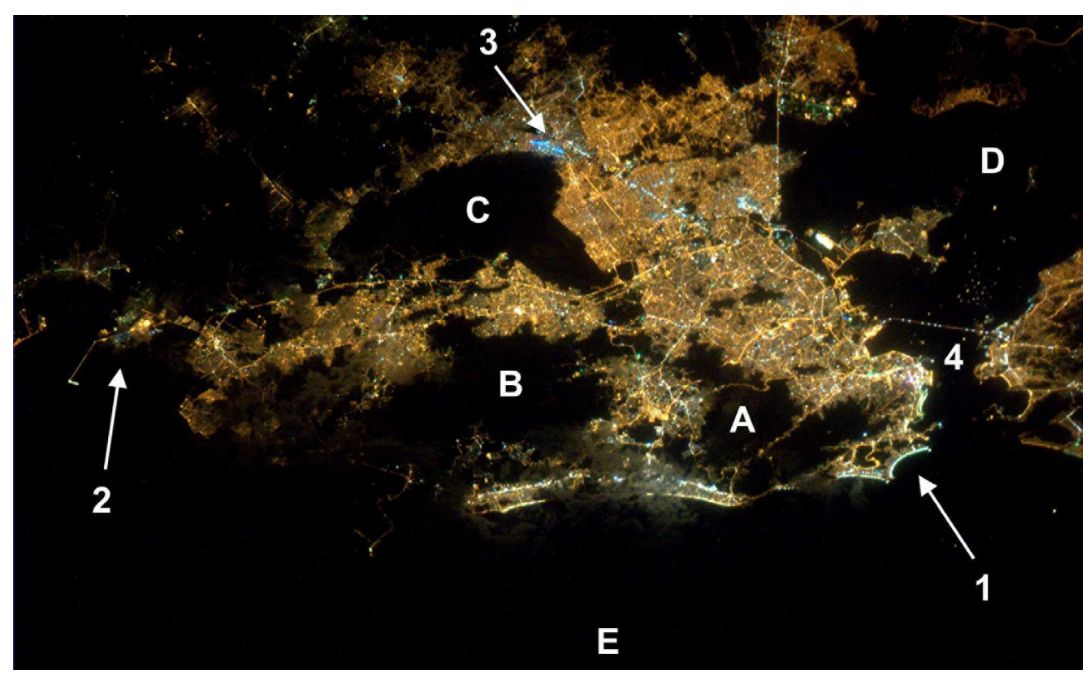

Figura 1. Fotografia aérea noturna que registra a Região Metropolitana do Rio de Janeiro ${ }^{3}$ Fonte: Fonte: NASA/ISS, 2014, com alterações realizadas pelo autor.

Apesar da grande visibilidade do tema da mobilidade nas pesquisas do campo das ciências sociais, pouco tem sido discutido sobre a mobilidade noturna, ou seja, as formas de deslocamento das pessoas no espaço urbano durante o período noturno. Obviamente, os problemas relacionados aos congestionamentos adquiriram centralidade sobre o tema, muito em razão da precarização das condições de vida nas grandes cidades, decorrente do adensamento populacional e do esgotamento dos sistemas de transporte público urbano. Um dos efeitos comumente citados é o congestionamento nas principais vias urbanas após o horário de trabalho, usualmente entre as 16 e 19 horas. Este problema leva à criação de estratégias espácio-temporais por parte da população e a inclusão de tais estratégias no planejamento dos gestores dos sistemas de transporte coletivo. Nesse sentido, as cidades latino-americanas apresentam casos ainda mais dramáticos em virtude das limitações orçamentárias por parte dos governos locais, da concentração de concessões para poucas empresas, do rápido crescimento do uso de veículos particulares, da densa e mal articulada estrutura urbana, dentre outros fatores.

3 As áreas assinaladas indicam alguns pontos de referência para a região; as áreas com luminosidade indicam ocupação humana; e as áreas escuras indicam áreas onde ainda predominam elementos naturais: florestas, lagoas, campos, oceano, baías etc. Pontos A, B e C: maciços costeiros; D: Baía de Guanabara; E: Oceano Atlântico; 1: Praia de Copacabana; 2- Porto de Itaguaí; 3- Rodovia Rio-São Paulo; 4- Ponte Rio-Niterói. 
De um modo geral, nos últimos anos, com o incremento do trabalho noturno, ${ }^{4}$ das duplas jornadas, dos serviços 24 horas, das atividades educacionais noturnas, dos fluxos de informação e da dispersão dos centros noturnos para além dos centros metropolitanos diurnos, uma nova demanda parece requisitar uma reorganização do urbano (Gwiazdzinski, 2005). Esta demanda possui um vínculo também com a vida noturna, o lazer e o entretenimento, com as atrações culturais, esportivas, boemias e sexuais, mais tradicionais do período. $\mathrm{O}$ aumento das atividades noturnas exige, portanto, uma nova carga de deslocamentos noturnos.

Usualmente o problema da mobilidade noturna está condicionado à diminuição da oferta dos serviços de transporte público após o horário de pico vespertino, ou seja, após as 20 horas, e não antes de sua retomada diurna entre as 4 e 6 horas da manhã. Quando ele não cessa completamente, em virtude dos períodos de manutenção dos equipamentos, ele tende a ter sua oferta bastante reduzida, aumentando o intervalo de tempo entre as composições, como no caso dos ônibus (figura 2). Seguramente, esta oferta também se encontra desproporcionalmente distribuída em toda a cidade, resultando em diferentes estratégias espaciais associadas aos lugares de lazer, trabalho e moradia.
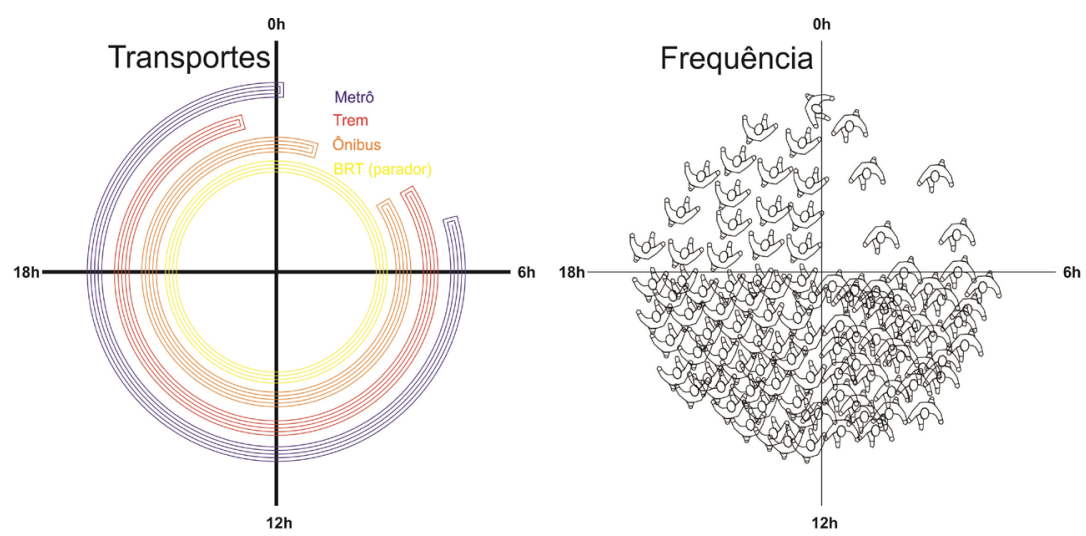

Figura 2. Cronotopias (relógios gráficos) para a frequência de usuários e de transportes

Fonte: elaboração própria a partir de dados coletados para o município do Rio de Janeiro em 2013.

4 Este artigo tratará especificamente dos deslocamentos gerados a partir das atividades de lazer noturno, as quais incluem também o trabalho noturno, o qual não será abordado diretamente aqui, mas que merecerá dedicação futura como um desdobramento deste esforço inicial. 
Em virtude dessa breve exposição, optamos por dividir o texto em três partes. A primeira apresentará muito brevemente o debate sobre a mobilidade urbana e suas implicações para as práticas sociais noturnas. A segunda tratará dos aportes metodológicos e dos instrumentos de pesquisa utilizados para decifrar algumas das estratégias de mobilidade noturna no contexto metropolitano do Rio de Janeiro. A terceira parte será dedicada às estratégias de deslocamento noturno em diferentes escalas. Acreditamos que em boa medida alguns exemplos das estratégias adotadas pela população poderão enriquecer o temário da mobilidade cotidiana da população de uma metrópole como o Rio de Janeiro, fornecendo caminhos para pesquisas comparativas e novas aproximações metodológicas ao tema.

\section{Vida noturna e mobilidade urbana}

A noite não costuma ser um tema comum nos estudos urbanos. O espaço dedicado a ela na descrição das cidades e das práticas urbanas é relativamente pequeno. As pesquisas sobre a vida noturna costumam se concentrar sobre o processo de ocupação social da noite (Melbin, 1987), sobre as tecnologias de iluminação (Schivelbusch, 1995) e sobre os comportamentos sociais (Palmer, 2000). O passado da vida social noturna tende a estar no centro das preocupações de sociólogos, historiadores e geógrafos. O crescente interesse pela vida noturna tem se desdobrado em outras pesquisas que procuram valorizar o aspecto econômico da noite, como tempo de trabalho e de lazer em uma sociedade que estaria em constante operação, 24 horas por dia (Gwiazdzinski, 2005). Estes trabalhos têm se desenvolvido em torno da ideia de uma economia noturna (Bianchini, 1995), caracterizada pelos fluxos de mercadorias, pelo consumo e entretenimento, pela gentrificação e pela sua associação com transformações culturais e econômicas mais gerais das sociedades urbanas (Chatterton e Hollands, 2003; Roberts, 2006; Talbot, 2007; Robinson, 2009). As implicações das transformações na economia urbana parecem ser significativas, tanto no que se 
refere às formas e funções urbanas, quanto naquilo que diz respeito à produção, à circulação e ao uso social da noite.

De modo bastante geral se observa que a noite aparece como um ingrediente que de alguma forma transforma a vida urbana, realçando alguns aspectos e esmaecendo ainda outros. Em um contexto acadêmico de crescente interesse pelo tema da vida noturna nas cidades, alguns temas parecem receber grande atenção, em virtude de sua pertinência para a vida cotidiana da população: insegurança, esvaziamento dos espaços públicos, desorientação, segregações socioespaciais, etc. Dentre este variado conjunto de problemas encontra-se a mobilidade noturna e sua relação com a organização interna das cidades. Desde 2009 temos trabalhado sobre o tema da vida social urbana durante o periodo noturno, com especial interesse sobre os fenômenos em sua dimensão espacial. A partir de pesquisas sobre a espacialidade da iluminação artificial, seus significados e papéis no ordenamento noturno urbano, e sobre os planos, projetos, práticas, circuitos e lugares da vida noturna carioca, formou-se um conjunto de problemas para futuras pesquisas.

Uma das conclusões mais gerais das pesquisas prévias foi de que a noite possui os seus próprios circuitos ou, de outra maneira, que com o avanço da noite novos circuitos são formados a partir de novos interesses sociais. Este fenômeno já foi observado por outros autores (Margulis, 1997; Magnani, 2005) e parece ter um alto grau de correlação com as atividades desenvolvidas durante o período noturno, mais especificamente com aquelas que estão direta ou indiretamente ligadas ao lazer. A entrada da noite parece contribuir para mudanças na organização interna dos fluxos e das concentrações no tecido urbano, estabelecendo novas centralidades, novos ritmos e novas estratégias de circulação.

Entendidas enquanto ações organizadas espacialmente, as práticas sociais desenham estes circuitos, os quais podem ligar estâncias ou centros que concentram as atividades noturnas. Aqui se pode dizer que há uma nítida correlação entre a perspectiva de uma geografia das temporalidades, ou melhor, práticas sociais que 
marcam o espaço a partir de deslocamentos (Hagerstrand, 1967). A ideia central exposta é a de que o conjunto de trajetos individuais formariam circuitos espaciais característicos da vida noturna de uma cidade, roteiros a serem seguidos para a realização de algumas práticas sociais. Estes conjuntos de deslocamentos individuais conformam um padrão que tende a ser a parte observável do fenômeno da mobilidade urbana noturna.

O movimento diário da população precisa ser repensado em alguns pontos quando se trata do período noturno. Primeiro, em termos de densidade: os deslocamentos entre as 18 e 06 horas são significativamente reduzidos em virtude da manutenção de postos de trabalho nos "horários comerciais" (figura 2). Segundo, em termos de recorrência e estabilidade: a noite é mais facilmente influenciada por variações nas ofertas de serviços do que o dia, tendo os fins de semana (sextas-feiras e sábados) como momentos de maior presença de indivíduos nas ruas (figura 3). Terceiro, em termos de centralidades: os centros de atração noturnos não costumam ser os mesmos que aqueles do período diurno, pois há, frequentemente, uma organização funcional das atividades noturnas, associada a valores, modismos e estratégias comerciais que não correspondem necessariamente àquelas pensadas para o diurno (figuras 4 y 5 ).

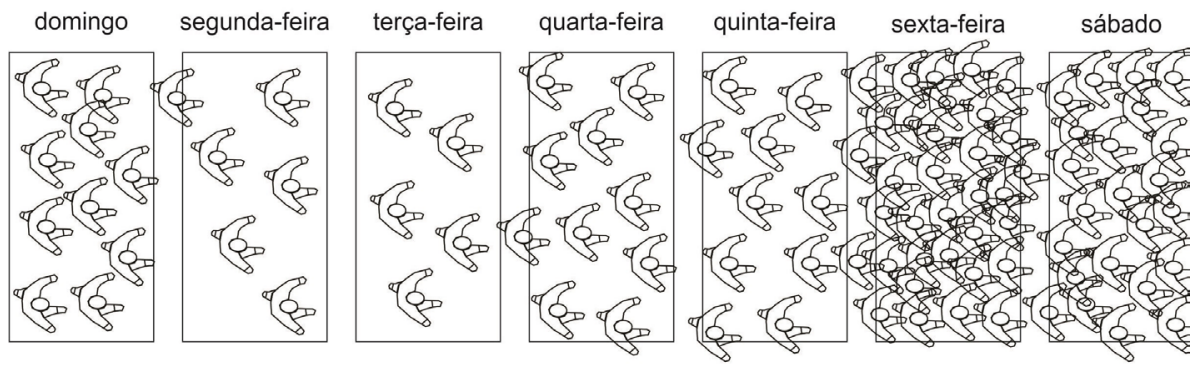

Figura 3. Frequência de pessoas nos espaços públicos à noite ao longo da semana Fonte: elaboração própria a partir de dados coletados para o município do Rio de Janeiro em 2013. 


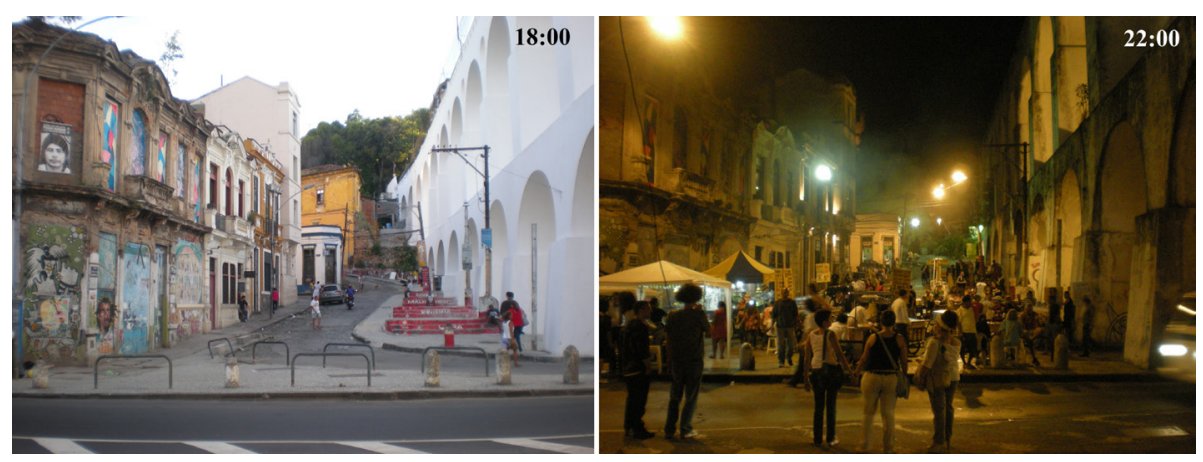

Figuras 4 y 5. Comparação de um mesmo lugar em momentos diferentes. ${ }^{5} \mathrm{Na}$ imagem da esquerda (18:00) há poucas ocupações das calçadas e ruas; na imagem da direita (22:00) observa-se a ocupação por pessoas, barracas e vendedores

Fonte: acervo do autor, 2011.

Estes pontos nos indicam que para se pensar a mobilidade noturna devemos de alguma maneira pensar as práticas sociais que ocorrem nos centros noturnos. São elas que oferecem, em um primeiro momento, a indicação dos nós que compõem a rede de fluxos noturnos em uma cidade. Dentro deste quadro ainda bem pouco explorado, espera-se analisar as modalidades que compõem o sistema de mobilidade noturna no município do Rio de Janeiro, suas características mais gerais, suas funções sociais e suas formas de apropriação pela população. Este caminho tem sido percorrido por meio da identificação de diferentes trajetórias, bem como as suas razões de deslocamento e lugares de concentração e permanência durante o período noturno. O objetivo final é refletir sobre a relação entre as centralidades estabelecidas no período noturno e as práticas sociais de deslocamento e permanência da população em tais centros. Com isso se acredita que um esboço de uma mobilidade urbana noturna possa ser estabelecido para o momento atual do Rio de Janeiro.

5 Observações tiradas em sextas-feiras, mas com um intervalo de tempo de alguns meses 


\section{Observando as práticas de deslocamento da população na noite do Rio de Janeiro}

A escolha de uma trajetória de pesquisa envolve um processo de reflexão sobre o estatuto do observador, visto que o seu papel frente àquilo que observa é ativo e tende a influenciar o seu conteúdo. Neste sentido, cada etapa da investigação foi construída tendo em consideração o lugar do observador, os instrumentos de aproximação da realidade observada e o caminho de análise que aproximaria cada abordagem realizada em campo. Assim, em um primeiro momento, o problema da mobilidade noturna foi observado de forma bastante distanciada, a partir de dados coletados e já debatidos por terceiros, como aqueles contidos no Plano Diretor de Mobilidade Urbana, criado pelo governo do estado do Rio de Janeiro. Este primeiro momento nos forneceu a visão do sistema de transportes, das principais razões de deslocamentos e os horários de circulação da população.

O segundo momento da pesquisa se voltou para os problemas dos fixos, complementando a discussão dos fluxos metropolitanos e concentrando o olhar sobre os centros noturnos. Em certa medida, queriamos saber para que lugares as pessoas iam e o que havia nesses lugares. Para isso, um extenso levantamento das ofertas de comércio e serviços foi realizado especificamente para o município do Rio de Janeiro, reduzindo a nossa área de observação pela primeira vez. Após o levantamento e a definição de categorias e indicadores, realizamos uma classificação de tais estabelecimentos e um Índice de Concentração das Atividades Noturnas foi criado se baseando no modelo do Índice de Desenvolvimento Humano das Nações Unidas. Este índice foi ainda reclassificado a partir de métodos de estatística espacial a partir do software ArcGis, resultando em um mapa que nos indicava os principais centros noturnos do município (figura 6). 


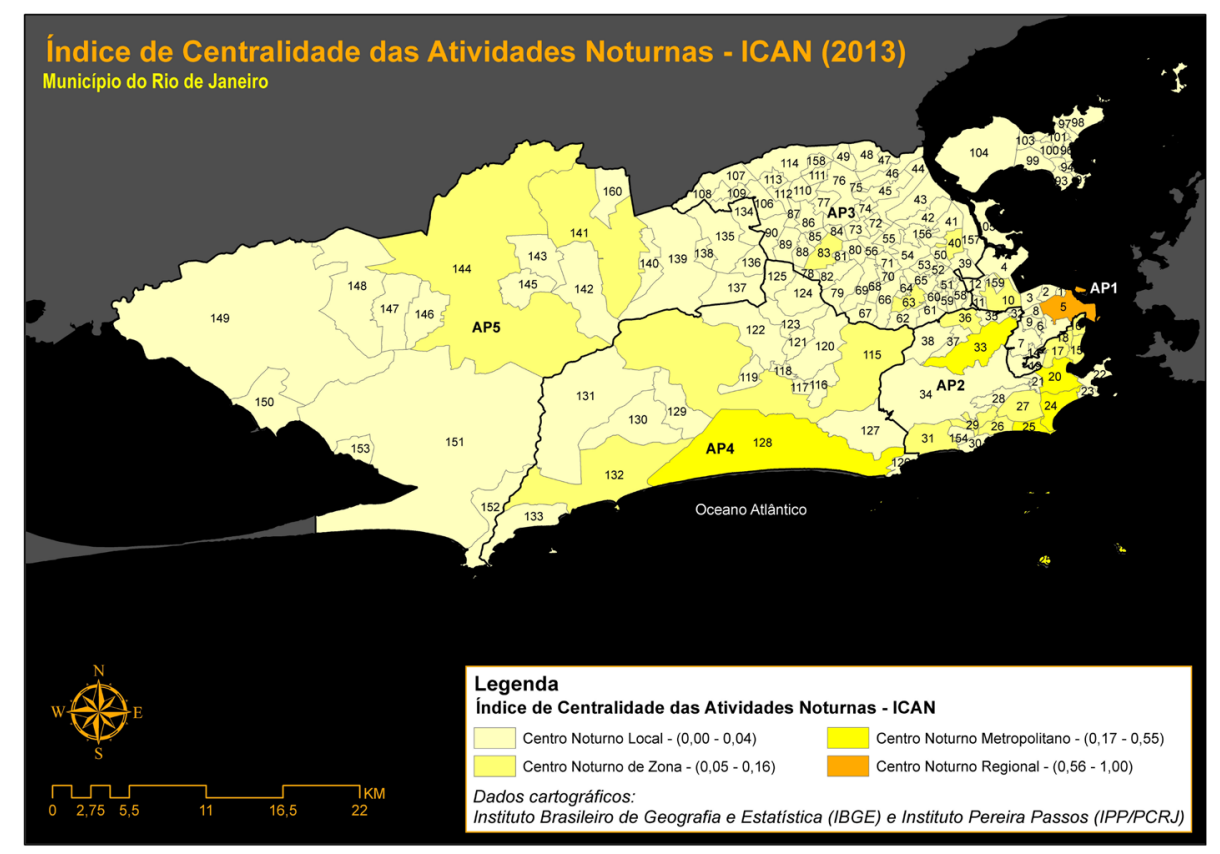

Figura 6. Mapa do Índice de Concentração das Atividades Noturnas para o município do Rio de Janeiro com os dados para o ano de $2013^{6}$

Fonte: elaboração própria a partir dos dados do cadastro de empresas municipal e da Telelistas, 2014.

Com os dados dos fluxos metropolitanos e dos centros municipais foi possivel observar a ocorrência de dois processos correlatos: a concentração no centro administrativo do município do Rio de Janeiro e a dispersão de centros menores em direção às zonas sul e oeste do município. O passo seguinte foi a definição dos centros e dos principais deslocamentos para a inserção de uma observação mais próxima da vida noturna no município do Rio de Janeiro. A escolha inicial foi pela observação direta e pelo acompanhamento de trajetórias e concentrações por meio de croquis e fichas de campo. A ideia central era observar algumas áreas definidas como centros noturnos da cidade do Rio de Janeiro, acompanhando os circuitos e as flutuações de densidade de públicos nos lugares, seguindo

\footnotetext{
6 Alguns dos bairros observados empiricamente: Centro (n.5); Copacabana (n.24); Méier (n.63); Madureira (n.83); Barra da Tijuca (n.128); e Campo Grande (n.144).
} 
método já realizado por autores como Whyte (1980) e Zeisel (1984). Este caminho foi escolhido tendo também como referência a obra de Henri Lefebvre (1992), a qual nos permitiu entender as relações entre ritmos lineares, mais lentos e progressivos, e ritmos cíclicos, que tendem a ter menor duração e variar em razão de circunstâncias localizadas. Com isso, unimos a pesquisa empírica mais tradicional com uma análise espacial que permitiu acompanhar os ritmos e sua relação com a mobilidade cotidiana da população, chegando, afinal, a uma teoria das redes, das ligações entre os centros e os circuitos que os ligam.

A proposta de Lefebvre (1992) em relação à análise dos ritmos apresenta a possibilidade de compreender a cidade como um conjunto de múltiplas temporalidades colocadas em jogo cotidianamente. Por isso, para Lefebvre, não se trata de um estudo sobre a singularidade, mas de como o ajuntamento de ritmos diferentes em um dado lugar cria um padrão cíclico dos ritmos. Para Lefebvre, sempre que há interação entre um lugar, um tempo e um gasto de energia, há ritmo. Este ritmo é fundamentalmente formado por repetições. Se avançarmos teoricamente sobre a questão podemos mesmo chegar nas considerações feitas por Doreen Massey (1994) e assumir que os espaços observados são formados por encontros de trajetórias, fluxos de diferentes ordens que se encontram em uma unidade observada ao longo de um período de tempo.

O último investimento empírico se deu em uma ainda mais reduzida escala de observação, aquela dos usuários e suas práticas individuais e coletivas no espaço, ou seja, as suas trajetórias nos centros e entre os centros. As práticas cotidianas ligadas ao noturno podem ser agrupadas segundo padrões de comportamentos associados aos cenários da vida noturna. Novamente, podemos compreender os significados relacionados aos lugares a partir de dois elementos fundamentais: os percursos e as estâncias que compõem as práticas sociais no espaço e que possuem ritmos próprios. É bem comum que nos trabalhos que estudam a vida noturna se dê maior atenção aos lugares em que se concentram os indivíduos do que às suas trajetórias. Em geral, sabemos as características das atividades e as formas 
de relação, mas não entendemos como os indivíduos lá chegaram e como se deslocam nesses lugares. Neste sentido, esta fase da pesquisa se apoiou em observações realizadas em áreas centrais de vida noturna, bem como o acompanhamento de seus deslocamentos ao longo da noite, resultado de acordos que nos permitiram seguir por um breve período suas práticas. Neste momento, identificados como pesquisadores, adentramos em seus roteiros, ouvimos suas reclamações e tentamos compreender a lógica espacial de suas decisões sobre as práticas noturnas. Parte desse processo será apresentada a seguir, a partir de recortes de escala que se iniciam no cenário metropolitano e terminam em caminhadas pelas ruas dos centros noturnos do município do Rio de Janeiro.

\section{Mobilidade urbana noturna na metrópole carioca}

Refletir sobre a mobilidade noturna em uma cidade como o Rio de Janeiro exige que se pense o problema na escala metropolitana. $O$ principal modo de deslocamento da população é o transporte coletivo, sendo responsável por mais de $70 \%$ das viagens realizadas por veículos motorizados, em uma crescente participação do metrô e do trem, como indicado no último Plano Diretor de Transporte Urbano do Governo do Estado do Rio de Janeiro (2016). A concentração das atividades comerciais, dos serviços, das instituições públicas e privadas nos centros municipais, especialmente no carioca, ainda mobiliza um fluxo de pessoas e de produtos cotidianamente nas mesmas direções. O centro do município do Rio de Janeiro, por exemplo, concentra mais de 500 mil trabalhadores formais, em sua maioria nos setores de comércio e serviços, que se deslocam diariamente em transportes coletivos (quase 90\%), levando, em média, praticamente $50 \mathrm{mi}-$ nutos no deslocamento entre sua residência e o trabalho, segundo dados do Instituto de Estudos do Trabalho e Sociedade (IETS) sobre as Centralidades da Região Metropolitana do Rio de Janeiro (2016).

A grande centralidade exercida pelos tradicionais bairros comerciais e administrativos vem sendo, no entanto, reduzida com 
o crescimento das áreas urbanas periféricas, concorrendo para a atração de fluxos metropolitanos. No caso da referida pesquisa realizada pelo IETS, nota-se que novas centralidades ou subcentros comerciais têm se estabelecido na região metropolitana. Em geral, tais fluxos estão fortemente dependentes do transporte coletivo, mesmo na Zona Oeste do município do Rio, onde o transporte individual concorre mais diretamente com os coletivos. A concentração do deslocamento diário residência-trabalho ou residência-estudo é bastante significativa, representando cerca de $75 \%$ do total. O lazer representa apenas $7 \%$ das razões de deslocamento, o que nos permite dizer que os centros são nós dedicados mais claramente aos postos de trabalho.

Em trabalho recentemente publicado, Góis (2015) sugere também uma hierarquização dos centros noturnos para o município do Rio de Janeiro. Neste caso, a localização das atividades de comércio e de serviços relacionados à vida noturna manteve uma correlação com os centros diurnos. Mais uma vez o Centro do Rio apareceu como a área de maior nível hierárquico, seguida pela Barra da Tijuca, Copacabana, Botafogo, Tijuca, Méier, Campo Grande e Madureira. No entanto, a densidade dos serviços é significativamente menor, cerca de $10 \%$ em relação ao diurno. Assim, verifica-se a hipótese de que o trabalho noturno é bem menos comum em relação ao trabalho diurno, mantendo o modelo tradicional de quadro de horários (8h-17h). Em virtude disso, a flutuação horária das viagens possui um padrão do tipo pico-vale intermitente, ou seja, deslocamentos que ocorrem no início da manhã e no final da tarde, entremeados por deslocamentos da hora do almoço. Em geral há permanência de grande fluxo entre as seis horas da manhã e dezenove horas da noite, com picos às sete horas, ao meio dia e às dezessete horas (todos com cerca de dois milhões de viagens por hora). O período de picos diurnos é intercalado por um vale profundo entre as vinte horas da noite e as cinco da madrugada. O uso de transporte motorizado coletivo cai drasticamente a partir das dezenove horas $(4,1 \%)$, chegando ao mínimo de $0,1 \%$ às duas horas da manhã e voltando a crescer a partir das quatro horas $(2,1 \%)$, como pode ser observado no gráfico abaixo (figura 7). 


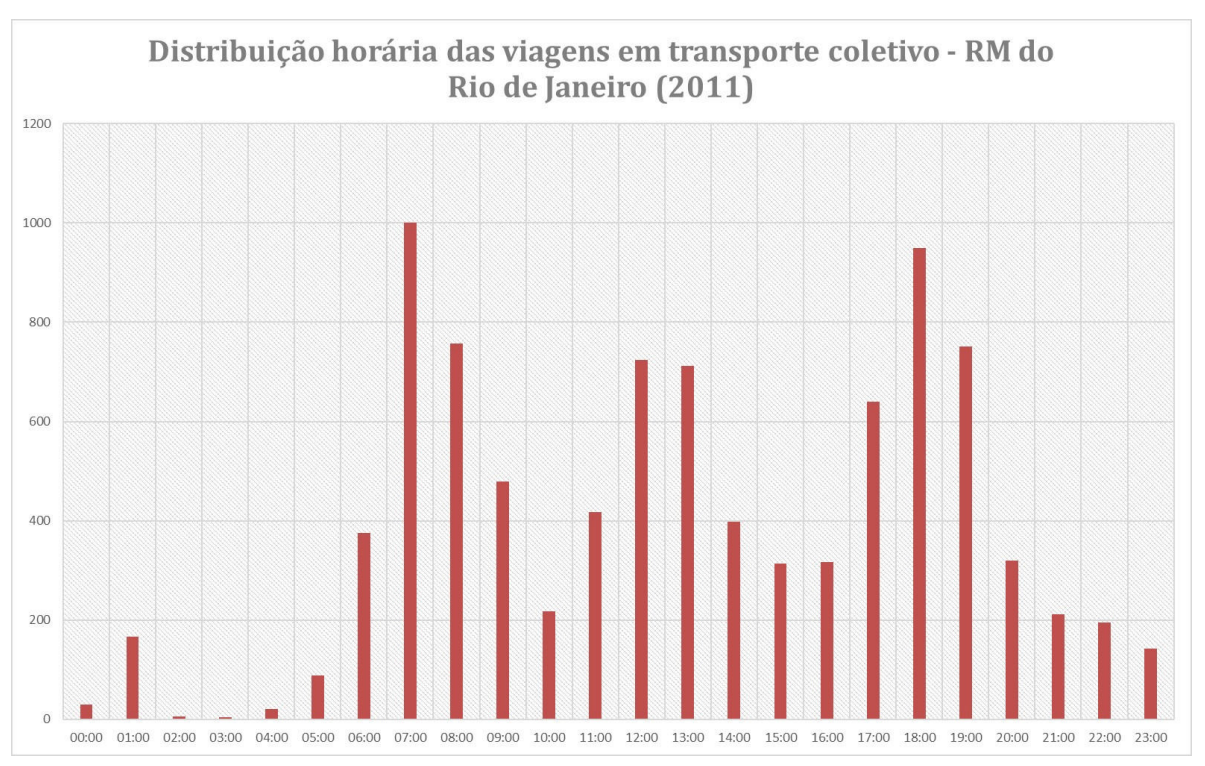

Figura 7. Distribuição horária das viagens em transporte coletivo Fonte: Plano Diretor de Transporte Urbano da Região Metropolitana do Rio de Janeiro, 2015.

Em geral, todas as formas de transporte tendem a reduzir o número de viagens durante o período noturno. No entanto, segundo dados apresentados no PDTU de 2015, podemos estimar que entre as 20 e as 05 horas temos, em média, cerca de dois milhões de viagens sendo realizadas, seja em veículos particulares, coletivos ou não motorizados. Ainda que este total represente apenas cerca de $20 \%$ do total de viagens, ele é um relevante indicador do montante de pessoas que estão supostamente realizando atividades durante o período, quer sejam atividades de lazer, quer sejam ações relacionadas ao trabalho.

A queda de uso dos transportes motorizados durante a noite pode estar relacionada a diversos fatores como a oferta de trabalho noturno, bastante reduzida em comparação ao trabalho diurno; os horários de funcionamento de centros de lazer e entretenimento, os quais, em geral, operam no máximo até às vinte e duas horas, como shopping centers, restaurantes e cinemas; a reduzida oferta de transporte coletivo, os quais reservam os horários entre meia-noite e quatro da manhã 
para realizarem a manutenção do sistema, como é o caso do metrô e dos trens, que não operam neste horário; a flutuação dos picos de atividades de lazer ao longo da semana, que tendem a se concentrar nos fins de semana, especialmente nas sextas-feiras e sábados; a associação com o problema da segurança; ou mesmo a disponibilidade de áreas públicas ou de atividades de lazer e entretenimento noturno, o que poderia criar uma regionalização da mobilidade à noite em torno dos centros noturnos metropolitanos, que como vimos parecem criar um eixo entre o centro da cidade e a Barra da Tijuca.

A regionalização do transporte coletivo também parece contribuir para algumas centralidades constituídas. As mais de mil linhas de ônibus que operam na região metropolitana tendem, em geral, a captar os fluxos de passageiros em direção à área central da cidade. Da mesma forma, as áreas de entroncamento e de integração do metrô e dos trens se concentram no centro da cidade (figura 8). À noite, como afirmado anteriormente, outros centros ganham relevância, sem que mudanças quantitativas ocorram na oferta de meios de transporte para a população.

Alguns elementos ajudam ainda a agravar a situação de aparente esvaziamento do período noturno e o relativo estrangulamento da oferta de meios de locomoção pela metrópole. Por sinal, a imobilidade noturna também resulta de uma diferenciada apropriação do urbano pela população segundo suas características socioeconômicas. Os dados do PDTU (2016) apontam que dependendo do município onde reside, da idade, do gênero, da renda e da escolaridade há menor probabilidade de que uma pessoa faça uma viagem entre dois pontos na metrópole. No total, cerca de $45 \%$ da amostra da população respondeu que não faria um deslocamento no dia da entrevista. A taxa de imobilidade sobe para $60 \%$ se considerarmos municípios limítrofes, como Tanguá, Seropédica e Mangaratiba. Em relação à idade, para aqueles que possuem mais de 60 anos a taxa pode chegar a $70 \%$, entre aqueles que ganham até dois salários mínimos a taxa chega a $55 \%$ e entre os analfabetos a quase $90 \%$. Isto indica a hipótese de que os deslocamentos noturnos são afetados também pelas características da população. ${ }^{7}$

Parece ser fundamental que estes pontos sejam cobertos por pesquisas futuras, especialmente em relação ao gênero e às barreiras que podem existir para o deslocamento e permanência das pessoas nos espaços públicos. Sem dúvida, há diferentes formas de apropriação do noturno implicadas pela menor participação de setores da sociedade. 


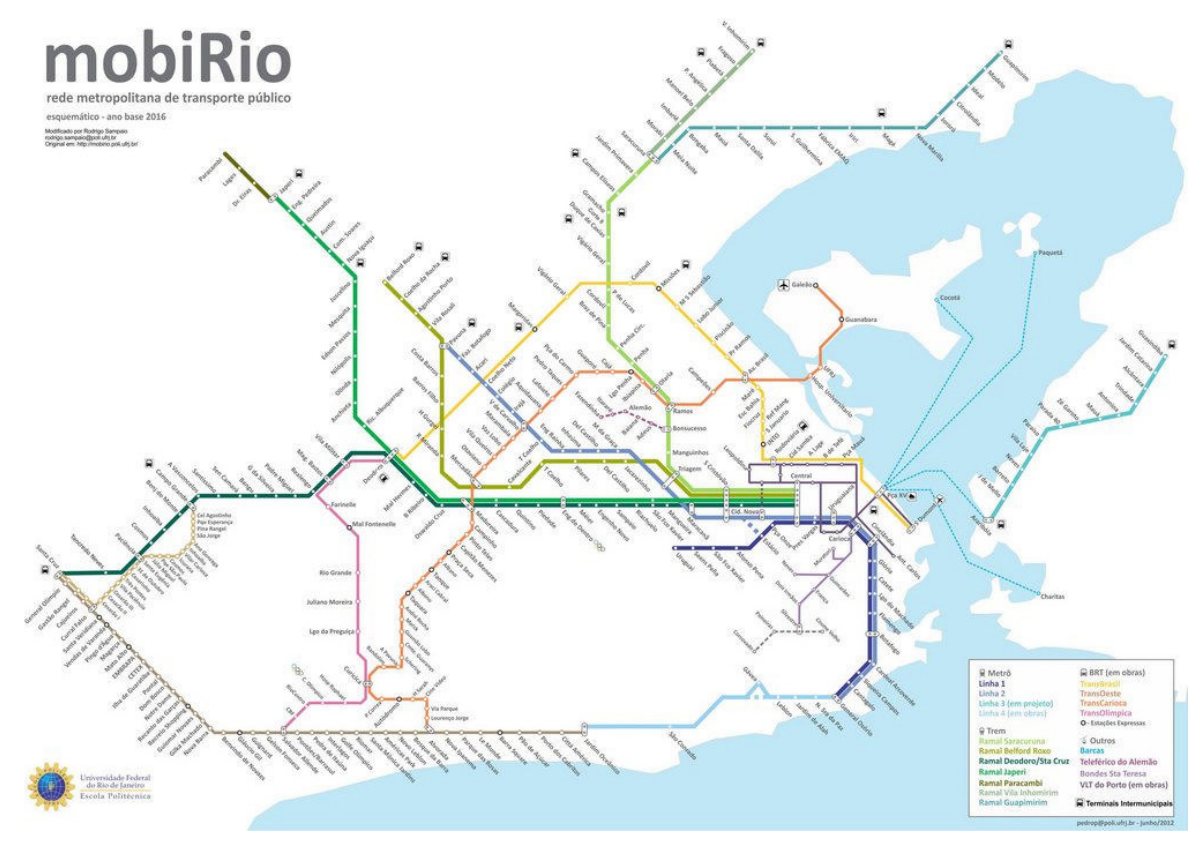

Figura 8. Mapa da Rede de Transportes Coletivos da Região Metropolitana do Rio de Janeiro

Fonte: Mobi Rio, 2016.

\section{Circuitos e estratégias de mobilidade noturna no Rio de Janeiro}

A mobilidade é um fenômeno social de caráter relacional, no qual os indivíduos produzem marcas e sentidos ao longo do percurso que realizam, o que envolve estruturas construídas, políticas de ordenamento e planejamento territorial, o meio urbano, a cultura de um povo e sua história, bem como os significados associados aos meios de deslocamento (Cresswell, 2006). A mobilidade é, assim, também uma potência, uma prática entre o desejado, o possivel e o realizado (Lévy, 2001). A condição relacional da mobilidade demanda, portanto, estratégias espaciais que vão muito além da mera dimensão física, da métrica do deslocamento e do imperativo da distância-tempo. 
Inclusive, por isso, os circuitos de relações entre indivíduos e entre estes e a estrutura urbana são recorrentemente reorganizados a partir das práticas espaciais que surgem como estratégias de adaptação aos problemas cotidianos. Neste sentido, a mobilidade pode ser entendida como uma prática social de deslocamento no espaço, a qual inclui não só os sistemas, modos, estruturas e funções dos objetos de transporte, mas também as ações, os desejos, as performances e as potencialidades de indivíduos e grupos de se deslocar nesse espaço (Gutiérrez, 2012).

Podemos notar que há uma importante implicação para a vida noturna nos espaços públicos que podemos extrair através de evidências empíricas. Em primeiro lugar, os congestionamentos têm motivado o surgimento e o prolongamento de atividades de happy hour, após o horário de trabalho. Em segundo lugar, as horas perdidas no trânsito têm impulsionado também o surgimento de escalas de trabalho mais flexiveis, com horários de entrada e saída que tendem a não mais reproduzir o padrão industrial comum até meados da década de 1980. Em terceiro lugar, alguma dose de sociabilidade tem sido adicionada a partir da interação entre os usuários dos transportes urbanos, seja através da interação entre passageiros em ônibus presos a engarrafamentos ou passageiros apinhados em vagões de metrô, seja entre motoristas de carros interagindo em meio ao trânsito caótico.

De qualquer forma, estas transformações nas relações com o transporte parecem ter produzido efeitos sobre o uso e quem sabe até mesmo sobre a definição dos lugares de sociabilidade. Além disso, os problemas de mobilidade parecem ter afetado também a localização de alguns lugares de sociabilidade noturna, deslocando centralidades para áreas anteriormente consideradas de passagem. A espera por horários menos congestionados tem se tornado uma atividade mais rotineira, o que se desdobra em uso noturno de espaços da cidade, como nas áreas no entorno de centrais ferroviárias, terminais de ônibus e estações de metrô. No Rio de Janeiro esta relação pode ser percebida nas proximidades dos grandes eixos de transporte como a Central do Brasil, o centro do bairro de 
Botafogo e as cercanias do Shopping Nova América, no bairro de Del Castilho.

Além desses desdobramentos relacionados à mobilidade diurna nas grandes cidades, a noite aparece em si como um momento de flexibilização da ideia de mobilidade. A desigual acessibilidade e mobilidade urbanas durante o período noturno, ou seja, a concentração de circulação entre algumas áreas em detrimento de outras rotas, privilegiando trajetórias durante a noite. Este processo tem certamente grande visibilidade na cidade do Rio de Janeiro, como pode ser observado a partir de três estratégias que parecem recobrir de forma mais comum algumas áreas da cidade.

a) O uso de veículos particulares produzindo um circuito veloz entre os pontos centrais da vida noturna entre os bairros da Barra da Tijuca e Ipanema, como restaurantes, bares e casas noturnas frequentadas, em sua maioria, por jovens entre 16 e 25 anos;

b) O uso de transporte público por moradores dos bairros da Zona Sul e Tijuca, articulando espaços públicos centrais para a vida noturna e estabelecimentos privados; e

c) A prática da circulação a pé em diversas áreas da cidade e que compreende um público mais variado que busca associar a circulação ao lazer e ao reconhecimento dos símbolos relacionados à diversão noturna. Em alguns casos poder circular pelo bairro garante que a noite possa se estender até o horário em que os meios de transporte público voltam a funcionar.

Estas estratégias afetam diretamente o uso dos espaços públicos da cidade, pois incorporam as práticas dos usuários, segundo apropriações diferentes dos espaços. Estas formas de apropriação podem ser entendidas como padrões que se articulam a estas outras escalas de mobilidade faladas anteriormente: a escala metropolitana e a escala urbana (figura 9). As três estratégias atuam na escala metropolitana e ajudam a concretizar os fenômenos de concentração em poucos centros noturnos, tornando visiveis os padrões de circulação noturna, especialmente 
em relação às duas primeiras estratégias. Veremos agora os padrões na escala local, ou seja, nos centros noturnos, onde predomina a última estratégia em meio ao espaço público e aos estabelecimentos privados.

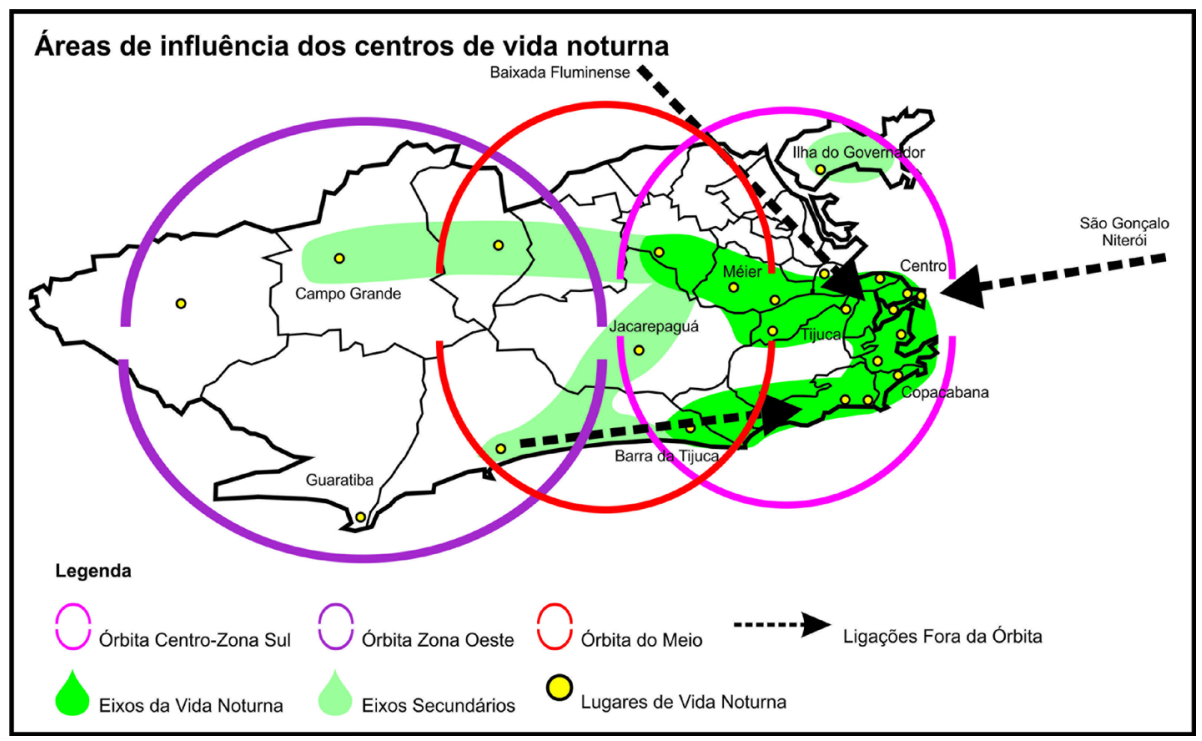

Figura 9. Áreas de influência dos centros de vida noturna

Fonte: elaboração própria a partir dos dados coletados em campo no município do Rio de Janeiro em 2013.

\section{Padrões de trajetórias noturnas}

Ao se observar o fluxo de pessoas durante uma noite de sexta-feira em diversos lugares da cidade do Rio de Janeiro, nota-se, em um primeiro momento, o seu confuso movimento nos espaços públicos, a concentração em inúmeros pontos e a variedade de comportamentos. Tamanha dispersão de trajetórias, pontos e interesses é comum às grandes cidades e já foi descrita por outros autores como sendo até mesmo aquilo que definiria o urbano (Jacobs, 2006). Essa aparente confusão possui, no entanto, uma organização, um ritmo próprio que repercute a rotina das trajetórias, dos circuitos e das práticas sociais. Poderíamos mesmo ir 
adiante e afirmar que tais repetições se conformam enquanto padrões de trajetórias noturnas. Estes padrões são formados pela repetição de práticas sobre um substrato material que qualifica as ações dos usuários dos espaços. A relação entre arquitetura e práticas móveis parece ter, assim, centralidade na conformação de tais padrões.

Nas pesquisas realizadas em alguns centros de vida noturna na cidade do Rio de Janeiro, as observações demonstraram o quanto o pedestrianismo é um fator comum a estes centros. Na maioria dos casos, áreas que se caracterizavam pela disponibilidade de calçadas, vias fechadas ao trânsito de veículos ou praças costumavam concentrar um maior número de pessoas, as quais, de forma geral, circulavam pelos espaços públicos, definindo um circuito noturno. Outro fator importante é a presença de estabelecimentos que oferecem alguma forma de serviço tido como importante para as práticas noturnas de lazer, especialmente o comércio de álcool e de comidas rápidas. No entorno de estabelecimentos comerciais deste tipo costumam se concentrar grupos e indivíduos durante um determinado período (figura 10). Por fim, a conectividade destes centros a outras áreas da cidade por meio de um maior número de entroncamentos de transportes foi um fator tido como significativo na concentração de usuários.

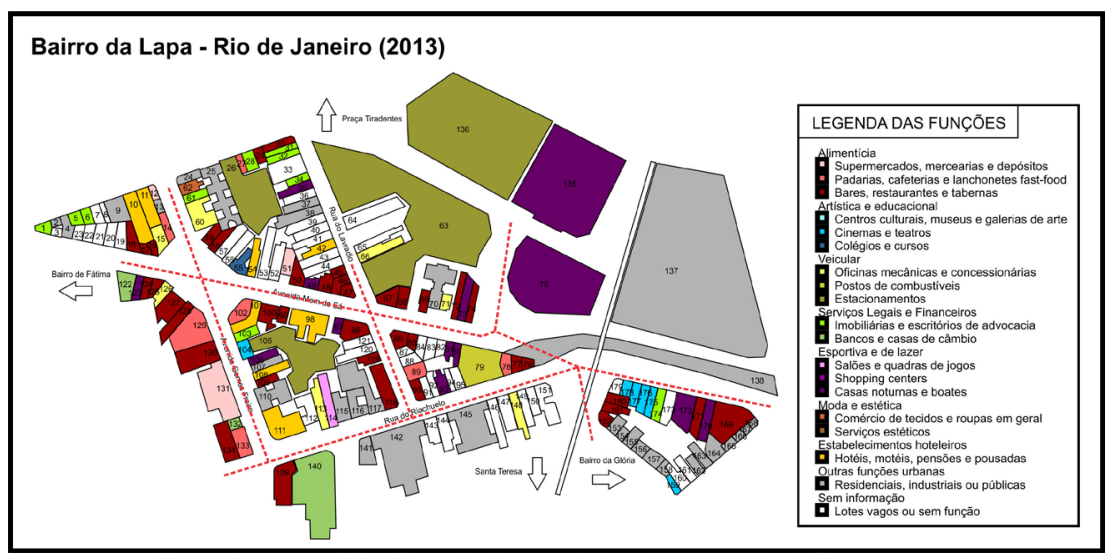

Figura 10. Croqui que indica os usos do solo urbano e as trajetórias no centro do bairro da Lapa, região central, Rio de Janeiro

Fonte: elaboração própria a partir dos dados coletados em campo entre os anos de 2012 e 2013. 
A partir destes três fatores -espaços para pedestres, atividades noturnas de lazer e conectividade com outras áreas-foram observadas áreas de concentração noturna de pessoas e seus circuitos. As áreas escolhidas possuíam características diferentes em relação as suas respectivas estruturas urbanas, densidades e oferta de serviços. A primeira se notabilizara pela histórica associação à vida noturna e se localiza na zona periférica do centro municipal, no atual bairro da Lapa. A segunda área compreende um subcentro comercial localizado no coração do subúrbio carioca, no bairro do Méier. Por fim, a terceira área se localiza em um dos marcos da expansão litorânea da elite carioca, no bairro da Barra da Tijuca. Em cada área foram produzidos croquis -como os observados na figura 10- que permitiram acompanhar os fluxos de pessoas em relação aos espaços físicos e meios de transporte. A partir deles foram criados padrões (figura 11) que ressaltavam os principais circuitos nos lugares:

a) Um padrão linear: a circulação se dava em uma direção, respeitando uma sequência de atividades ao longo da noite, o que normalmente incluía um momento de abertura, um momento de realização da noite propriamente dita e um momento de conclusão, realizados, usualmente em lugares diferentes e que reuniam também um conjunto de práticas que se diferenciavam umas das outras. Os exemplos mais comuns surgiram dos circuitos dos jovens na Barra da Tijuca, onde "a noite" poderia começar em um bar ou loja de conveniência de um posto de combustiveis, onde se encontrariam os amigos, seguir para alguma casa noturna na região e terminar em lanchonetes ou barracas de fast food nas cercanias das casas noturnas, como ponto de parada antes do retorno para casa.

b) Um padrão circular: as trajetórias circulares são mais comuns nas áreas internas dos bairros, especialmente nos setores comerciais do centro de um bairro. Neste caso não há uma única via, mas um conjunto formado por um ou mais quarteirões que possuem atividades comerciais e serviços de consumo recorrente, às vezes até mesmo segmentadas em diferentes ruas, mas 
compondo um conjunto mais ou menos unitário. Assim, o ato de circular a pé faz parte de uma "peregrinação" em busca de lugares mais movimentados, que ofereçam opções de entretenimento ou de lugares mais sossegados, que se desassociem das áreas de maior concentração. Nesse caso se trata de mais uma estratégia de visibilidade, na qual circular se torna um ato de apresentação ao lugar e aos seus usuários. Ao mesmo tempo, essa é uma forma de reconhecimento do lugar e de identificação com seus signos. A ação de fechar ruas ou criar apresentações em praças tende a reforçar este padrão, estabelecendo o sentido do movimento das pessoas, como pode ser observado no caso do bairro do Méier.

c) Um padrão de múltiplos circuitos: em alguns casos, o padrão de trajetórias não pode ser traçado seguindo uma orientação única e acaba por se estabelecer a partir de um jogo de possibilidades de encontros e de orientações que subvertem os traçados mais comuns. Neste caso não há uma lógica geométrica na distribuição dos pontos; uma ordem que guie a prática caminhante dos indivíduos. Torna-se, na verdade, um padrão orientado pela densidade de atividades, as quais acabam criando um padrão difuso, expressão da centralidade do lugar e de sua volatilidade em relação aos eventos extraordinários. No Rio de Janeiro o melhor exemplo de uma área na qual as trajetórias noturnas são complexas é o bairro da Lapa. Em quase toda a sua extensão o bairro possui atividades atrativas aos usuários. Em meio a esta multiplicidade de trajetórias, torna-se bem comum que os circuitos não obedeçam somente às preferências dos usuários, os quais podem escolher trajetórias diferentes, em busca de novidades. A área da Lapa é, aliás, reconhecida por esta característica de ser um lugar que permite diversas estratégias de apresentação ao público. A localização do bairro, entre duas áreas densamente povoadas da cidade -a Zona Sul e a Zona Norte- e a proximidade com estações de metrô e paradas de ônibus facilitam ainda mais a confluência dos públicos. 

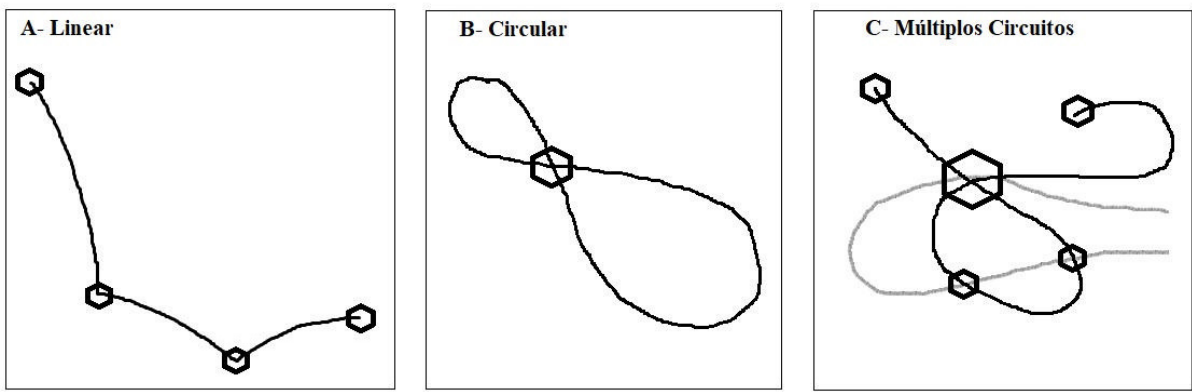

Figura 11. Padrões de trajetórias dos circuitos da vida noturna no municipio do Rio de Janeiro

Fonte: elaboração própria a partir da generalização dos dados obtidos para o município do Rio de Janeiro entre os anos de 2011 e 2015.

Estes padrões de trajetórias e de concentrações são constituídos pela materialidade que os delimita e que sugere percursos, mas também são parte das práticas ligadas ao noturno que reforçam as suas marcas sobre o espaço. Alguns desses padrões demoraram para se constituir, não sendo absolutamente dados pela morfologia, mas organizados ao longo do tempo a partir da reinvenção das práticas sociais. Em outros casos, um padrão circular encontra-se em estágio de deterioração, e novas trajetórias começam a se estabelecer segundo um padrão linear, ligando as áreas a partir de um roteiro da vida noturna, uma moda, no sentido de um modelo absorvido por uma maioria durante um dado período de tempo. Com isso, queremos dizer que os padrões são o resultado de um momento de observação e que são passiveis de mudança em virtude de transformações nas práticas de sociabilidade noturna.

Além de suas limitações em relação às escalas do tempo, os padrões também apresentam variações em termos de escalas espaciais. Em alguns casos, a combinação dos padrões ou a densidade formadora de um padrão em um espaço relativamente grande pode criar áreas ou polos razoavelmente extensos, abarcando bairros inteiros para atividades mais fortemente ligadas ao noturno, como no caso da ligação por veículos particulares entre os bairros da Barra da Tijuca, São Conrado, Leblon e Ipanema. Os polos, se agrupados dentro de um contexto ou de 
uma conjuntura econômica maior, podem fazer parte de uma rede que interliga centros de concentração noturna na cidade, produzindo circuitos mais velozes dentro da cidade, articulando municípios na escala metropolitana. Ao mesmo tempo, um ponto dentro de uma área pode fazer parte de uma rede em outra escala, incorporando orientações e estratégias que não possuem lógica do lugar, como se dá no caso de filiais de corporações internacionais que se inserem dentro de um contexto e modificam a orientação geral de um lugar em virtude de seus objetivos externos. Até mesmo a área ou o polo pode fazer parte de uma rede de cidades que não dormem, se integrando ao mundo como uma área de extrema importância para a vida noturna em termos globais, sinalizando a sua importância como centro de diversão noturna, compondo um álbum de imagens de cidades à noite. Esses pontos de reflexão são mais alguns dos possiveis desdobramentos deste artigo e compõem um campo de pesquisas sobre o urbano, o noturno e a mobilidade.

\section{Conclusões}

$\mathrm{Na}$ formação dos circuitos noturnos a escala de ação dos indivíduos e dos grupos é um importante tema para a interpretação não só das suas razões, mas também, de uma forma mais geral, é uma maneira de compreender a própria articulação interna da cidade, seus sistemas de transporte, seus eixos de ligação e seus obstáculos para a circulação. Neste sentido, a proposta inicial de pesquisa sobre os circuitos urbanos noturnos teve como um dos seus desdobramentos a investigação sobre a mobilidade urbana da população carioca durante o período noturno. Se há um reconhecido debate sobre a mobilidade urbana, tornando-a, inclusive, parte central da vida urbana contemporânea, muito pouco parece ter sido comentado sobre a flutuação de tais usos e deslocamentos ao longo do dia. Em relação à flutuação horária, percebemos que há na Região Metropolitana do Rio de Janeiro uma permanência de um grande fluxo entre as seis horas da manhã e as dezenove horas da noite, representando cerca de $80 \%$ dos deslocamentos diários. Entre as 19 horas e as 04 horas da manhã há um relativo decréscimo, impactando significativamente a oferta de serviços no período noturno. 
A queda de uso dos transportes motorizados durante a noite revela que a metrópole carioca ainda é essencialmente diurna. A diversificação dos horários de trabalho e dos períodos de manutenção das redes de transporte ainda é tímida e poucas iniciativas têm tentado pensar o noturno dentro do planejamento mais geral das cidades. O transporte coletivo, em particular, permanece altamente concentrado nas áreas nobres da capital fluminense e a baixa frequência noturna tende a reforçar este quadro de desigual distribuição socioespacial. Observa-se que os postos de trabalho e as atividades de lazer ligados ao noturno permanecem fortemente concentrados em tradicionais bairros boêmios, nos mais importantes centros comerciais da metrópole. A descentralização como um processo ainda em andamento promete oferecer novas possibilidades para moradores da região metropolitana.

Os problemas de mobilidade parecem ter afetado também a localização de alguns lugares de sociabilidade noturna, deslocando centralidades para áreas anteriormente consideradas de passagem. Isto possui pelo menos dois desdobramentos visiveis. Em primeiro lugar, a espera por horários menos congestionados tem se tornado mais comum, o que se desdobra em uso noturno de espaços da cidade, como nas áreas no entorno de centrais ferroviárias, terminais de ônibus e estações de metrô, transformando a visão de que seriam lugares degradados e perigosos. Em segundo lugar, espaços de fluxos têm se tornado espaços de espera ou de conflito, tornando a mobilidade em um tema para a discussão da publicidade. Ruas, viadutos, passarelas, vias expressas são redecoradas pela paralisia do automóvel e pela circulação de ambulantes e de ciclistas (Parente Ribeiro e Musset, 2015).

Há ainda na escala dos centros noturnos novas rotinas que surgem como alternativas para a vida noturna em espaços públicos. A busca pelo lazer, mas também a busca por relações de sociabilidade, faz com que o caminhar seja uma estratégia de reconhecimento do espaço e dos padrões de interação social. Esta tática pedestre acaba compondo circuitos da sociabilidade que se desdobram em padrões de trajetórias em centros noturnos. Vimos que algumas 
destas trajetórias decorrem da tradicional relação entre espaço construído e comportamento social, mas que elas também denotam o comportamento como algo que muda ao longo do tempo, transformando a própria organização das áreas e os circuitos. Dessa forma, as estratégias de deslocamento na noite carioca podem ser observadas em diferentes escalas, percorrendo o problema da mobilidade metropolitana, urbana e local, seus modos, estratégias e relações, em termos que estabelecem um diálogo entre o deslocamento e a sociabilidade dentro do período noturno.

\section{Referências}

Bianchini, F. (1995). Night Cultures, Night Economies. Planning Practice and Research, 10(2), 121-126.

Chatterton, P. and Hollands, R. (2003). Urban Nightscapes: youth cultures, pleasure spaces and corporate power. London - New York: Routledge.

Cresswell, T. (2006). On the Move: mobility in the modern western world. London - New York: Routledge.

Docherty, I., Shaw, J. and Gather, M. (2004). State Intervention in Contemporary Transport. Journal of Transport Geography, 12(4), 257-264.

Edensor, T. (2011). Commuter: mobility, rhythm and commuting. In T. Cresswell and P. Merriman (Eds.), Geographies of Mobilities: practices, spaces, subjects (189-204). Londres: Ashgate Publishing.

Gakenheimer, R. (1999). Urban Mobility in the Developing World. Transportation Research Part A: Policy and Practice, 33(7), 671-689.

Góis, M. (2015). Paisagens Noturnas Cariocas: formas e práticas da noite na cidade do Rio de Janeiro (Tese Doutorado em Geografia). Instituto de Geociências, UFRJ, Rio de Janeiro. 
Gutiérrez, A. (2012). ¿Qué es la Movilidad? Elementos para (re) construir las definiciones básicas del campo del transporte. Bitácora Urbano Territorial, 21(2), 61-74.

Gwiazdzinski, L. (2005). La Nuit, Dernière Frontière de la Ville. La Tour d'Aigues: Éditions de 1'Aube.

Hagerstrand, T. (1967). Innovation Difusion as a Spatial Process. Chicago: University of Chicago Press.

Jacobs, J. (2006). Morte e Vida de Grandes Cidades. São Paulo: Martins Fontes.

Lefebvre, H. (1992). Rhythmanalysis: space, time and everyday life. Nova Iorque: Continuum.

Lévy, J. (2001). Os Novos Espaços da Mobilidade. GEOgraphia, 3(6), 7-17.

Lorimer, H. (2011). Walking: new forms and spaces for studies of pedestrianism. In T. Cresswell and P. Merriman (Eds.), Geographies of Mobilities: practices, spaces, subjects (pp. 19-34). Londres: Ashgate Publishing.

Magnani, J. (2005). Os Circuitos dos Jovens Urbanos. Tempo Social: Revista de Sociologia da USP, 17(2), 173-205.

Margulis, M. (1997). La Cultura de la Noche: la vida nocturna de los jóvenes en Buenos Aires. Buenos Aires: Biblos.

Massey, D. (1994). A Global Sense of Place. In D. Massey (Ed.), Space, Place and Gender (pp. 146-156). Minessota: University of Minessota Press.

Melbin, M. (1987). Night as Frontier. Nova Iorque: Free Press.

Palmer, B. (2000). Cultures of Darkness: night travels in the histories of transgression. Nova Iorque: Monthly Review Press.

Parente Ribeiro, L. and Musset, A. (2015). L'attente Comme Ressource: les vendeurs ambulants de Rio de Janeiro et de Tijuana. In L. Vidal and A. Musset 
(Eds.), Les Territoires de l'attente: migrations et mobilités dans les amériques (XIXe-XXIe siécle) (211-225). Rennes: Presses Universitaires de Rennes.

Roberts, M. (2006). From 'Creative City' to 'no go areas': the expansion of the night-time economy in british town and city centres. Cities, 23(5), 331-338.

Robinson, C. (2009). Nightscapes and Leisure Spaces: an ethnographic study of young people's use of free space. Journal of Youth Studies, 12(5), 501-514.

Schivelbusch, W. (1995). Disenchanted Night: the industrialization of light in the nineteenth century. Los Angeles: The University of California Press.

Talbot, D. (2007). Regulating the Night: race, culture and exclusion in the making of the night-time economy. Londres: Ashgate Publishing.

Whyte, W. (1980). The Social Life of Small Urban Spaces. Washington: Conservation Foundation.

Zeisel, J. (1984). Inquiry by Design: tools for environment-behaviour research. Cambridge: Cambridge University Press.

\section{Cómo citar este artículo}

Góis, M. P. F. (2018). Mobilidade noturna: estudo sobre os circuitos urbanos noturnos na cidade do Rio de Janeiro. Universitas Humanística, 85, 263-291. https://doi.org/10.11144/Javeriana.uh85.mnes 